\title{
Estimation of Age Using Dimensions of Apical Foramina of Teeth
}

\author{
Aklesha Behera ${ }^{1}$, Archana Santhanam², Herald J. Sherlin³, Gifrina Jayaraj, K.R. Don ${ }^{5}$ \\ 1,2, 3, 4, 5 Department of Oral Pathology and Microbiology, Saveetha Dental College and Hospitals, Saveetha \\ Institute of Medical and Technical Sciences (SIMATS), Saveetha University, Chennai, Tamil Nadu, India.
}

\section{ABSTRACT}

\section{BACKGROUND}

Forensic odontology is an ever growing and a flourishing science. The science deals in criminal laws by using dental knowledge. People who practice forensic odontology are called as forensic dentists. They are asked to determine the age, sex, race, occupation, previous dental history and various other determinants like DNA verification in unidentified human beings. Teeth are a very special tissue in the human body. Teeth are the only tissue which can survive through extreme climatic and environmental conditions like heat, cold etc. hence many a times retains its morphology. Age estimation has been studied by many researchers but age estimation methods have been incapable of providing the age estimation in older age groups. The study aims to determine the age using the dimensions of the apical foramen from middle age to old age groups.

\section{METHODS}

A descriptive ex vivo study, was done from December 2019 to March 2020. Freshly extracted teeth were collected and cleaned using hydrogen peroxide. The teeth selected were single rooted teeth like incisors, canine and premolars in the age group of 30 to 40 years, 41 - 50 years, 51 - 60 years and 61 - 70 years. Apical one third of the teeth was sectioned, mounted over a slide and placed perpendicular to the lens of the stereomicroscope. Using Mag Vision and Image J software, photomicrographs and measurements were taken. Data procured was tabulated and statistical analysis was done using Statistical Package for the Social Sciences (SPSS) version 20.

\section{RESULTS}

In 30 - 40 years age group, the mean diameter of all single rooted teeth was $0.35 \mathrm{~mm}$. Among the 41 - 50 years age group, the mean diameter was $0.43 \mathrm{~mm}$. In 51 - 60 years age group it was $0.41 \mathrm{~mm}$ and in the $61-70$ years age group, the mean diameter was $0.36 \mathrm{~mm}$. Pearson chi square $P$ value for incisor is 0.280 , canine is 0.223 and premolar is 0.326 .

\section{CONCLUSIONS}

Age estimation can be done using physiological dimensions of apical foramen. From the present study, dimensions of apical foramen decreases with increasing age due to cementum deposition.

\section{KEY WORDS}

Age Determination, Apical Foramen Diameter, Single Rooted Teeth
Corresponding Author: Dr. Aklesha Behera, Saveetha Dental College and Hospitals, Saveetha Institute of Medical and Technical Sciences (SIMATS), Saveetha University, Chennai, Tamilnadu, India.

E-mail:akleshabehera@gmail.com

DOI: $10.14260 / j e m d s / 2021 / 151$

How to Cite This Article:

Behera A, Santhanam A, Sherlin HJ, et al. Estimation of age using dimensions of apical foramina of teeth. J Evolution Med Dent Sci 2021;10(10):705-710, DOI: $10.14260 / \mathrm{jemds} / 2021 / 151$

Submission 29-09-2020,

Peer Review 03-12-2020,

Acceptance 10-12-2020,

Published 08-03-2021.

Copyright (c) 2021 Aklesha Behera et al. This is an open access article distributed under Creative Commons Attribution License [Attribution 4.0 International (CC BY 4.0)] 


\section{BACKGROUND}

Forensic odontology is a branch of forensic sciences, where the dentist uses his skills in personal identification in mass casualties, sexual assault, child abuse and other varied cases. The information obtained from examining the teeth or oral cavity is a document that is applicable in the court of law. According to Keiser-Neilson, forensic dentistry is "The branch of forensic medicine which in the interest of justice deals with the proper handling and examination of dental evidence and with the proper evaluation and presentation of the dental findings." 1

Forensic dentistry in India was established as Indian Association of Forensic Odontology (IAFO), in the year 2000. IAFO was officially registered in 2001 in Chennai, Tamilnadu. ${ }^{2}$

According to the American Board of Forensic Dentistry, dental identification is divided into four types: ${ }^{3}$

1. Positive identification: The antemortem and postmortem data is matched to establish that it is from same individual.

2. Possible identification: The antemortem and postmortem data has few consistent features, but because of quality of the records it is difficult to establish the identity.

3. Insufficient evidence: The data is not sufficient enough to reach a conclusion.

4. Exclusion: The antemortem and postmortem data is clearly not reliable.

Age estimation is a widely used technique in forensic dentistry, due to increased crimes leading to unidentified cadavers. It is specifically used to identify the age of individuals unable to procure the necessary document to reside in any country.

Age estimation is used to predict the age of a dead or living person and is one of the important analyses in forensic medicine and odontology for a variety of legal procedures. ${ }^{4}$ Important for identification of unidentified victims in crime scene investigations or accidents. Dentition also plays an important role, like dental maturity in estimating the chronological age of individuals. ${ }^{5}$ Age estimation can be used for constructing a biological profile, determination of age and sex in crime investigations, child labour, employment, status of majority, rape, adoption and eligibility for marriage. 6

Teeth are the hardest, well protected structures in the body and resist decomposition and high temperatures and are among the last ones to disintegrate after death. ${ }^{7}$ The principal basis of dental identification lies in the fact that the teeth are unique to an individual. Recent advances have shown various dental age estimation methods from clinical method, radiographic method, histological examination, physical and chemical analysis. Using various features like presence or absence of teeth, eruption staging, third molar analysis, dentition color, wearing diseases like attrition, cervical abrasions and microscopic tissue evaluation for accurate analysis of development of dentition or tissues, dentinal sclerosis and dead tracts. 4,5

Apical constriction is considered as the apical limit and the narrowest part of canal (minor diameter) is a morphologic landmark, usually widens as a funnel shape ending into the apical foramen as major diameter. ${ }^{8}$ There is a distance of 0.5 $\mathrm{mm}$ between minor and major diameter common among 25 years and $0.65 \mathrm{~mm}$ among age groups of 55 years $^{9}$ Morse et al. in 1994 have studied age estimation among older people with periapical radiographs with six parameters like coronal length, apical length, root canal length, cervical width, mid root width and apical width. ${ }^{10}$ There are various alterations in the root apex which may be due to pathological lesions, trauma, genetic variations, convexity of dentinal walls, periodontal lesions, etc. ${ }^{11}$ There are various studies showing age estimations using various factors, in this present study, we attempted to estimate age using the dimensions of apical foramina.

Despite the fact that a few apical morphology studies in Indian, Turkish and European populations have shown a great complexity but there are no studies regarding the apical foramen dimension and age estimation in the South Indian population. ${ }^{12}$ The purpose of this study was to correlate age and diameter of the physiological foramen in roots of extracted single rooted teeth in South Indian population.

\section{METHODS}

A descriptive ex vivo study was conducted using 38 single rooted teeth that had been recently extracted from the South Indian population. The reasons for extraction were periodontal, pulpal, orthodontic or prosthetic. Single rooted teeth that had complete root development were included in the study. Teeth with previously initiated therapy, endodontically treated or with apical resorption, were excluded from the study.

\section{Sample Collection}

A sample of total 38 single rooted teeth with mature apices of adult patients in the age range from 31 to 70 years were procured. These samples were collected from the department of Oral and Maxillofacial Surgery after extraction in a private dental institution in Chennai, Tamil Nadu, India. The approval for the study was taken from the institutional review board. Single rooted teeth like incisors, canine and premolars were collected according to 4 age groups. 31 to 40 years, 41 to 50 years, 51 to 60 years and 61 to 70 years. 8 teeth were collected in the 30 to 40 age group, 10 teeth were collected in 41 to 50 years, 9 teeth in 51 - 60 years, 11 teeth in 61 - 70 age groups.

\section{Preparation of Teeth}

After the extraction procedure, the teeth were washed in running water, debrided to remove remaining periodontal tissue and calculus, and deposited in a flask filled with saline solution. This flask was then labelled with the tooth type and patient age and sex. The roots were cut in a cross-sectional manner to a distance three to five millimetres from the anatomical apex with a diamond disk with abundant irrigation with saline solution. A total of 38 sections were obtained. These were then submerged in $5 \%$ sodium hypochlorite for 24 hours to disinfect the samples. Finally, they were submerged in hydrogenperoxide for an hour, washed in running water and dried with gauze. In the case of persistence of organic tissue in the apical foramen, a K 06 file was used to remove it. Sections were mounted over a slide for stereomicroscopic examination 


\section{Measurement of Apical Foramen}

The section of the teeth was mounted onto a slide, placed parallel to the magnifying lens and analyzed under a computer aided stereomicroscope (Lawrence \& Mayo (India) Pvt Ltd., Lawrence \& Mayo House, 274, Dr. D.N. Road, Fort, and Mumbai-400001. Model number: LM-52-3621, Serial number: 700152). Using Mag Vision software, photomicrographs of the apical foramen of the teeth specimen were taken and Image J Software was used to measure the dimensions of the foramen. Image $\mathrm{J}$ is a Java based image processing program developed at the National Institute of Health and the Laboratory for Optical and Computational Instrumentation (LOCI, University of Wisconsin). Image J uses the default calibration in pixel mode, hence the pixels were calibrated into micro scale with $0.1 \mathrm{~mm}$ markings. The measuring dialogue menu was set in millimetres and adjusted to three decimal places.

\section{Statistical Analysis}

Data was tabulated in an excel sheet. Statistical analysis was made using SPSS version 20 software. Descriptive statistics and within group comparisons were done using Pearson chisquare tests with $\mathrm{P}$ value $<0.05$ was considered to be statistically significant.

\section{RESULTS}

Total number of teeth selected were 38 in number. Selected teeth were divided according to their age groups. Dimensions of each apical foramen were measured in millimetres and tabulated. It was observed that under $30-40$ years of age group, the mean diameter of all single rooted teeth was 0.35 $\mathrm{mm}$. Among the 41 - 50 years of age group, the mean diameter was $0.43 \mathrm{~mm}$. In the $51-60$ years of age group was $0.41 \mathrm{~mm}$ and in the 61 - 70 years age group, the mean diameter was 0.36 mm respectively. (Table 1 )

Association was made between the teeth and age groups. The dimensions of incisors were assessed. Among $30-40$ years of age group, $57.14 \%$ of the teeth had their apical foramen measurements between $0.41-0.50 \mathrm{~mm}$. In $41-50$ years of age group, $75 \%$ of the teeth measured between 0.31 $0.40 \mathrm{~mm}$. In $51-60$ age groups, $28.57 \%$ of the teeth samples had their apical foramen diameters between $0.31-0.60 \mathrm{~mm}$. In the $61-70$ years age group, $75 \%$ of the teeth samples measured between $0.10-0.20 \mathrm{~mm}$. Pearson chi square P value was 0.280 , hence the association is statistically not significant. (Figure 1)

The same associations were made with canines. Among age groups of 41 - 50 years, $50 \%$ of the samples measured between $0.81-0.90 \mathrm{~mm}$ and $50 \%$ of the samples measured between $0.71-0.80 \mathrm{~mm}$. In 61 - 70 years of age group, $100 \%$ of the samples had their measurements between $0.21-0.30$ $\mathrm{mm}$. Pearson chi square $\mathrm{P}$ value was 0.223 , hence the association is statistically not significant. (Figure 2)

Associations were made with premolars. Among age groups of $30-40$ years, $100 \%$ of the samples measured between $0.41-0.50 \mathrm{~mm}$. In $41-50$ years of age groups, $25 \%$ of the teeth samples measured between $0.10-0.20 \mathrm{~mm}, 0.21$ $0.30 \mathrm{~mm}$ and $0.51-0.70 \mathrm{~mm}$ respectively. In $51-60$ years age groups, $100 \%$ of the samples are measured between 0.31 $0.40 \mathrm{~mm}$. In 61 - 70 years age groups measured between 0.41 - $0.60 \mathrm{~mm}$. Pearson chi square P value was 0.326 , hence the association is statistically not significant. (Figure 3 )

\begin{tabular}{|cc|}
\hline Age Group & Mean (mm) \\
30 - 40 years & $0.35 \mathrm{~mm}$ \\
41 - 50 years & $0.43 \mathrm{~mm}$ \\
51 - 60 years & $0.41 \mathrm{~mm}$ \\
61 - 70 years & $0.36 \mathrm{~mm}$ \\
\hline Table 1. Mean Diameters of Apical Foramen in Various Age Groups \\
\hline
\end{tabular}

\section{DISCUSSION}

Estimation of age using various parts of teeth has become a fast growing practice in forensic sciences. Since many years forensic scientists have been trying different methods for determining chronological age of the patients. Methods implied were radiological methods, teeth calcification methods, and skeletal maturation methods. In the present study we have tried determining the age by assessing the apical diameters of the teeth.

Previous studies have stated that the diameter of apical foramen changes in shape and diameter. This is due to deposition of cementum. In the present study, the mean value of diameter of single root teeth between 51 - 60 years and 61 70 years is $0.41 \mathrm{~mm}$ and $0.36 \mathrm{~mm}$. L. Awawdeh et al in 2019 found a significant association between age and narrowing of the diameter of apical foramen, which is in accordance with our study. ${ }^{13}$ According to a study made by Kuttler, the average diameter of apical foramen between 18 to 25 years was 502 microns and in the age group of 55 years and above, the average diameter was 681 microns, which is not in accordance with our study. According to Kuttler, diameter of the apical foramina increases with age due to apposition of cementum. ${ }^{9}$

According to a study conducted by Mizutani in 1992, labiolingual diameters in the apical foramen of the central incisors, the lateral incisors and the cuspids were $0.504 \mathrm{~mm}$, $0.452 \mathrm{~mm}$ and $0.425 \mathrm{~mm}$ respectively ${ }^{14} \mathrm{~A}$ study conducted by Gani et al confirmed that there is a statistical significant association between constriction of apical diameter with increase of age. ${ }^{14,15}$

Many studies have been conducted to know the age of children using the diameter of root apices. Yu-Chen Guo et al in 2015 conducted a study on northern Chinese children using Cameriere's methods. A linear regression formula was formulated where the mean difference between the European results and Chinese results was - 0.04 years. ${ }^{16}$

Similar study was conducted in South Africa in 2019, the interquartile range was 1.91 to 1.13 years. ${ }^{17}$ In German population, the interquartile range was 1.185 years. ${ }^{17,18}$ In the South Indian population, the sensitivity was $94.8 \%$ and 98.2 $\%$ for males and females, and the specificity was $58.7 \%$ and $62.8 \%$, respectively. ${ }^{19}$ In this study, and also with the support of previous literatures, it can be concluded that as age advances, the diameter of apical foramen decreases. Further study with large sample size, and ethnic groups should be done to be used in forensics. 


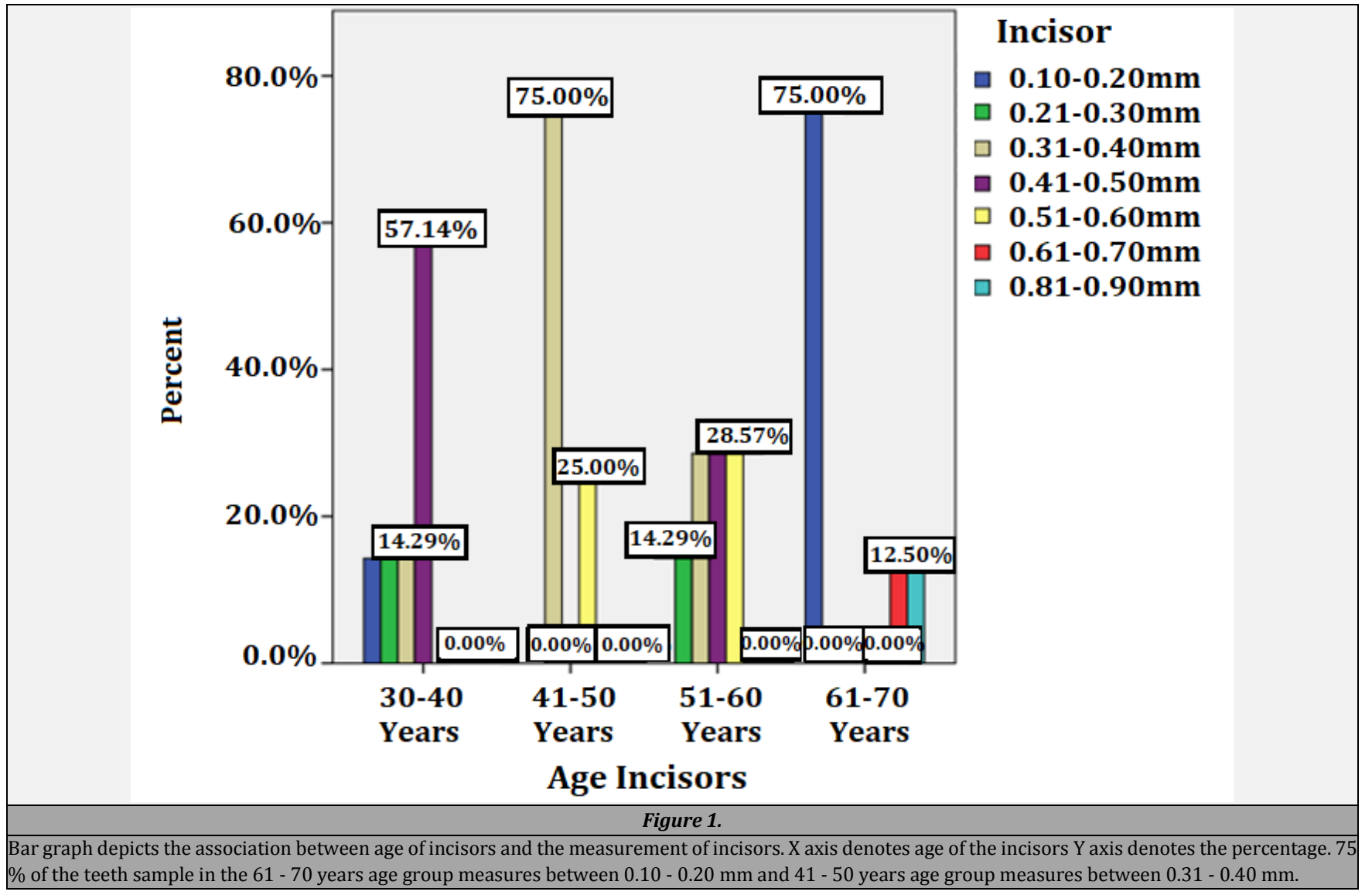

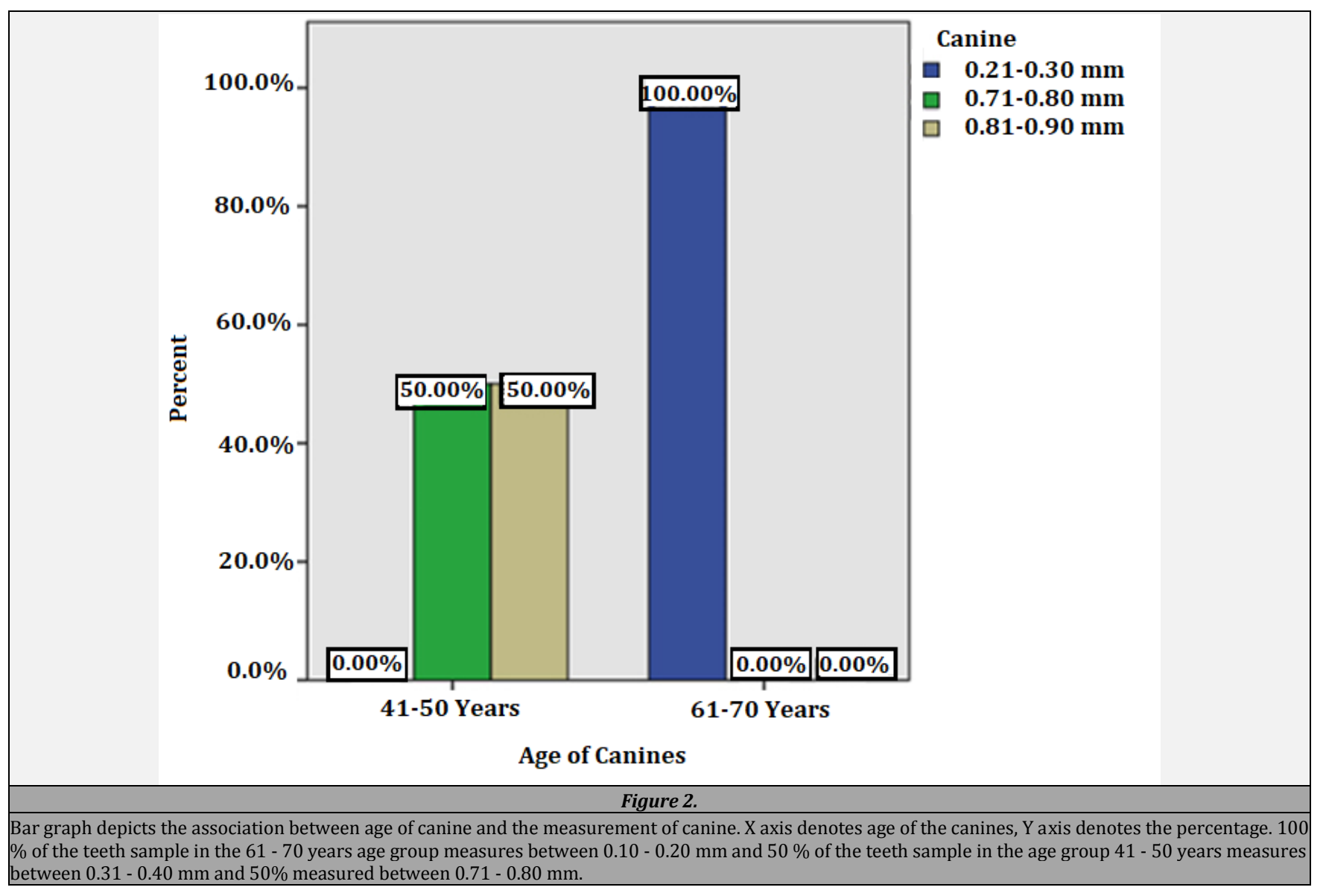




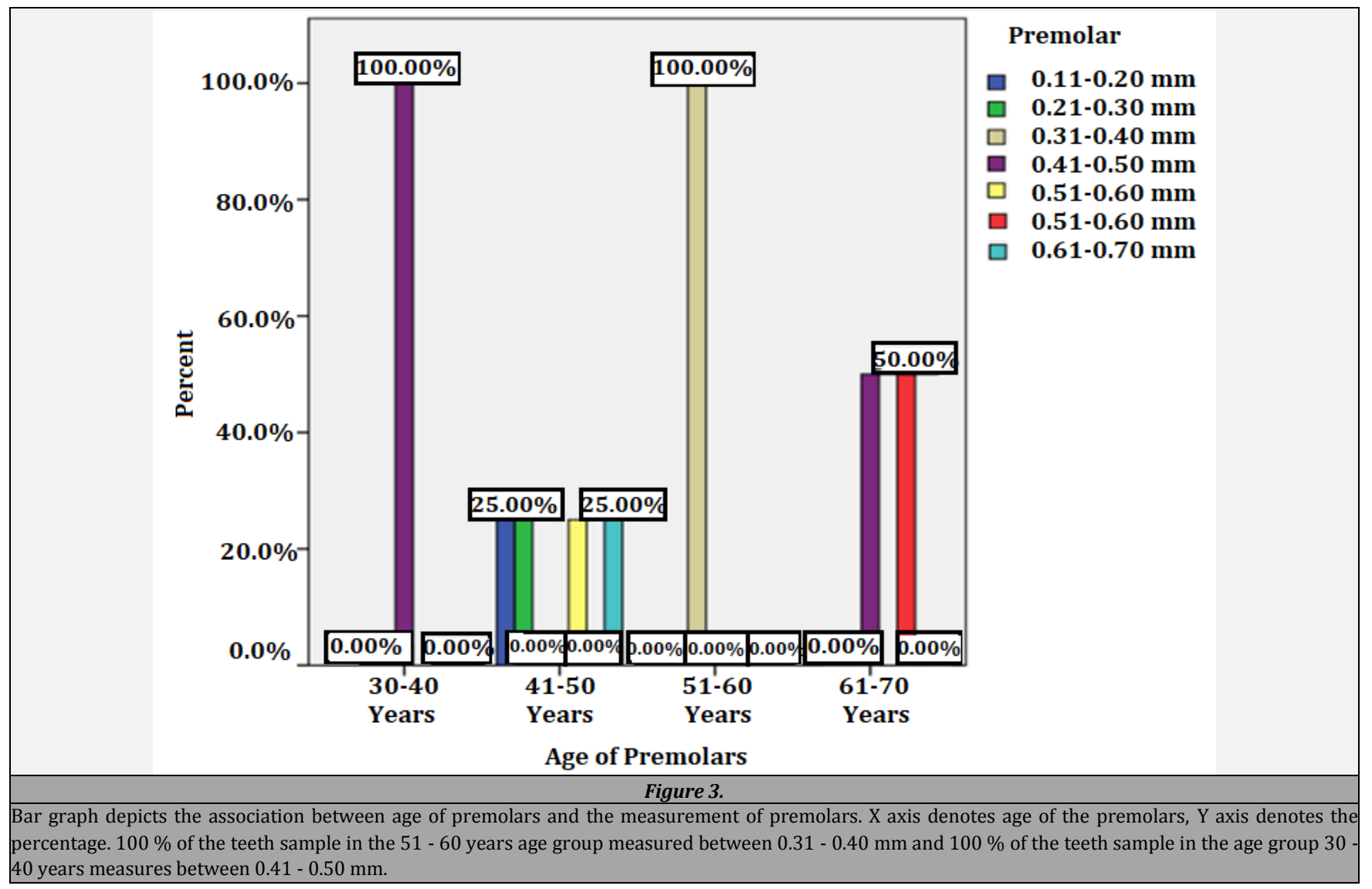

\section{CONCLUSIONS}

Age estimation can be done using physiological dimensions of the apical foramen. From the present study, we could conclude that dimensions of apical foramen decrease with increasing age due to cementum deposition.

Data sharing statement provided by the authors is available with the full text of this article at jemds.com.

Financial or other competing interests: None.

Disclosure forms provided by the authors are available with the full text of this article at jemds.com.

\section{REFERENCES}

[1] Keiser-Nielsen S. Person identification by means of the teeth: a practical guide. Bristol [England]: Wright 1980.

[2] Acharya AB. A decade of forensic odontology in India. J Forensic Dent Sci 2010;2(1):1.

[3] Rai B, Kaur J. DNA technology and forensic odontology. Evidence-Based Forensic Dentistry 2013: p. 163-7.

[4] Chaudhary R, Doggalli N. Commonly used different dental age estimation methods in children and adolescents. International Journal of Forensic Odontology 2018;3(2):50-4.

[5] Nayak S, George R, Shenoy A, et al. Age estimation in forensic dentistry-a review. International Journal of Scientific Research 2012;3(4):333-8.

[6] Acharya AB. Age estimation in Indians using Demirjian's 8-teeth method. J Forensic Sci 2011;56(1):124-7.

[7] Verma M, Verma N, Sharma R, et al. Dental age estimation methods in adult dentitions: an overview. J Forensic Dent Sci 2019;11(2):57-63.

[8] Ricucci D, Langeland K. Apical limit of root canal instrumentation and obturation, part 2. A histological study. Int Endod J 1998;31(6):394-409.

[9] Kuttler Y. Microscopic investigation of root apexes. The J Am Dent Assoc 1955;50(5):544-52.

[10] Morse DR, Esposito JV, Kessler HP, et al. Age estimation using dental periapical radiographic parameters. A review and comparative study of clinically based and regression models with the operation desert storm victims. Am J Forensic Med Pathol 1994;15(4):303-18.

[11] Aggarwal G, Bogra P, Gupta S, et al. Determination of apical constriction and apical foramen using electronic apex locator in vivo: comparison between vital and nonvital teeth. Saudi Endodontic Journal 2018;8(2):99105.

[12] Abarca J, Zaror C, Contreras W, et al. Morphology of the physiological apical foramen of maxillary premolars. Int J Morphol 2018;36(1):164-8.

[13] Awawdeh L, Fadaleh MA, Al-Qudah A. Mandibular first premolar apical morphology: a stereomicroscopic study. Aust Endod J 2019;45(2):233-40.

[14] Mizutani T, Ohno N, Nakamura H. Anatomical study of the root apex in the maxillary anterior teeth. J Endod 1992;18(7):344-7.

[15] Gani 0, Visvisian C. Apical canal diameter in the first upper molar at various ages. J Endod 1999;25(10):68991.

[16] Guo YC, Yan CX, Lin XW, et al. Age estimation in Northern Chinese children by measurement of open apices in tooth roots. Int J Legal Med 2015;129(1):179-86. 
[17] Angelakopoulos N, De Luca S, Palacio LAV, et al. Age estimation by measuring open apices in teeth: a new formula for two samples of South African black and white children. Int J Legal Med 2019;133(5):1529-36.

[18] Halilah T, Khdairi N, Jost-Brinkmann PG, et al. Age estimation in 5-16-year-old children by measurement of open apices: North German formula. Forensic Sci Int 2018;293:103.e1-8.

[19] Balla SB, Banda TR, Galic I, et al. Validation of Cameriere's third molar maturity index alone and in combination with apical maturity of permanent mandibular second molar for indicating legal age of 14 years in a sample of South Indian children. Forensic Sci Int 2019;297:243-8. 